\title{
Neoformação in vitro de Parte Aérea e Enraizamento Adventício de Brotações de Tabernaemontana catharinensis A. DC
}

\section{In vitro Neoformation of Aerial Part and Adventitious Rooting of Shoots of Tabernaemontana catharinensis A. DC}

\author{
Marcelo Vielmo Afonso*a; Juçara Terezinha Paranhos ${ }^{\mathrm{b}}$; Luciane Almeri Tabaldi ${ }^{\mathrm{b}}$; Aline Soares Pereira ${ }^{\mathrm{c}}$; Athos Odin \\ Severo Dorneles ${ }^{\mathrm{d}}$
}

\author{
anstituto Federal Farroupilha. RS, Brasil. \\ 'Universidade Federal de Santa Maria, Programa de Pós-Graduação Stricto Sensu em Agrobiologia. RS, Brasil. \\ 'Universidade Federal de Pelotas, Programa de Pós-Graduação Stricto Sensu em Sistemas de Produção Agrícola Familiar. RS, Brasil. \\ dUniversidade Federal de Pelotas, Programa de Pós-Graduação Stricto Sensu em Fisiologia Vegetal RS, Brasil. \\ *E-mail: marcelovielmo@yahoo.com.br
}

\begin{abstract}
Resumo
Plantas nativas com potencial medicinal têm acentuada valorização mundial, contudo, ainda muitas espécies requerem estudos ecológicos e fisiológicos, que auxiliarão na multiplicação e conservação das espécies. Assim se objetivou, neste trabalho, avaliar o efeito da 6-benzilaminopurina (BAP) associada ao ácido naftalenoacético (ANA) no estímulo de formação de brotações aéreas a partir de segmentos cotiledonares de Tabernaemontana catharinensis e posterior indução do enraizamento em cultivo suplementado com ácido indolbutírico (AIB). Segmentos cotiledonares de plântulas obtidas in vitro foram inoculados em meio de cultivo (MS), contendo diferentes combinações de BAP e ANA: $0,0 \times 0,0 ; 1,0 \times 0,1 ; 2,0 \times 0,2 ; 4,0 \times 0,4 ; 6,0 \times 0,6 \mathrm{mg} \mathrm{L}^{-1}$, respectivamente. Após a obtenção de brotações aéreas, as mesmas foram cultivadas em meio contendo AIB, por 30 dias, nas concentrações de 0,$0 ; 1,0 ; 2,0 ; 4,0$ ou $6,0 \mathrm{mg} \mathrm{L}^{-1}$. A organogênese direta de brotações adventícias foi induzida sem a necessidade de fitorreguladores de crescimento (BAP x ANA) no meio de cultivo. No entanto, houve um incremento no número de brotos e folhas, comprimento e massa fresca das brotações na presença dos fitorreguladores. A rizogênese em brotações aéreas, quando cultivadas em meio enriquecido com $6,0 \mathrm{mg} \mathrm{L}^{-1}$ de AIB atingiu $80 \%$. As variáveis: comprimento, massa fresca e número de raízes foram potencializadas com adição de AIB. Portanto, os fitorreguladores de crescimento promovem a obtenção de um maior número de microplantas completas desta espécie, a partir de segmentos cotiledonares cultivados in vitro.
\end{abstract}

Palavras-chave: Planta Medicinal. Auxinas. Citocininas. Parâmetros Fisiológicos.

\begin{abstract}
Native plants with medicinal potential have outstanding worldwide appreciation, however still many species require ecological and physiological studies, which will assist in the species multiplication and conservation. Thus, the aim of this study was to evaluate the effect of naphthalene acetic acid (NAA) associated with 6-benzylaminopurine (BAP) on the stimulation of shoot formation from cotyledonary segments of Tabernaemontana catharinensis and subsequent induction of rooting in Indolbutyric-acid supplementation (IBA). Cotyledonous segments of seedlings obtained in vitro were inoculated in culture medium (MS) containing different BAP and NAA combinations: $0.0 \times 0.00 ; 1.0 \times 0.1$; $2.0 \times 0.2 ; 4.0 \times 0.4 ; 6.0 \times 0.6 \mathrm{mg} \mathrm{L}^{-1}$, respectively. After obtaining aerial shoots, they were cultivated in medium containing IBA, for 30 days, at concentrations of $0.0 ; 1.0 ; 2.0 ; 4.0$ or $6.0 \mathrm{mg} \mathrm{L}^{-1}$. Direct organogenesis of adventitious shoots can be induced without the need for growth phytoregulators (BAP $\times$ NAA) in the culture medium. However, there is an increase in leaf number, shoot length and fresh shoot weight in the presence of phytoregulators. The rhizogenesis in shoots when grown in medium supplemented with $6.0 \mathrm{mg} \mathrm{L^{-1 }}$ of IBA reaches $80 \%$. The variables length, fresh mass, and root number were potentiated with the IBA addition. Therefore, growth regulators make it possible to obtain a larger number of complete microplants of this species from in vitro cultivated cotyledonary segments.
\end{abstract}

Keywords: Medicinal Plant. Auxins. Cytokinins. Physiological Parameters.

\section{Introdução}

A diversidade da flora brasileira tem impulsionado o desenvolvimento da cadeia produtiva de plantas com potencial medicinal no Brasil (FRANCISCO et al., 2015). Tal interesse é produto da acentuada valorização mundial do uso de plantas medicinais. Ao mesmo tempo em que a Ciência intensifica os estudos sobre os efeitos das ervas, seu cultivo também requer o desenvolvimento de estudos ecológicos e fisiológicos passíveis de serem utilizados e o armazenamento de informações técnicas para a multiplicação e conservação dessas espécies (MAIA et al., 2009).

Nesse contexto, a espécie Tabernaemontana catharinensis A. DC. (Apocynaceae), nativa do Rio Grande do Sul(PEREIRA et al., 2008), popularmente conhecida como "cobrina" ou "jasmim-cata-vento" (LORENZI, 2009) demonstrou, em estudos fitoquímicos, ser rica em flavonoides, saponinas, terpenos, alcaloides e esteroides (BÉLO et al., 2009). Seus ramos possuem atividade antioxidante, revelando além da rutina, um glicosídeo de quercetina e ácido clorogênico (PIANA et al., 2014). O chá ou a infusão das folhas e cascas são utilizados na medicina popular brasileira como antídoto para picadas de cobra, para aliviar dor de dente, tratamento de feridas, herpes, tumores e, ainda, como hemostática, hipotensora e cardiotônica (PEREIRA et al., 2005).

Como nas demais plantas nativas, sua propagação ocorre através de sementes, contudo, essa via de propagação 
apresenta algumas desvantagens, como a falta de uniformidade, segregação de caracteres e longo tempo para a produção das mudas (NEPOMUCENO et al., 2009). Nesse sentido, a micropropagação tem se destacado na área florestal, especialmente, de espécies com potencial medicinal pela ampla possibilidade de aplicação para a obtenção de plantas com alta qualidade genética e fitossanitária, disponibilidade em proporções comerciais, redução da extração não controlada em seu habitat natural, na conservação e estocagem de germoplasma e por servir de base para outras técnicas biotecnológicas (XAVIER et al., 2009).

No entanto, a falta de protocolos eficientes de propagação limita aplicações de caráter agronômico e biológico, especialmente das plantas lenhosas (FERMINO JUNIOR; PEREIRA, 2012). O sucesso do cultivo in vitro de espécies vegetais é dependente de fatores associados à indução e ao controle da morfogênese, quanto à obtenção de brotos e raízes no processo de organogênese, tornando-se imprescindível o controle da composição do meio de cultura (MORAIS et al., 2014). As citocininas e auxinas são os fitorreguladores de crescimento mais utilizados na cultura de tecidos (PINHAL et al., 2011), contudo, a concentração é um importante fator para maximizar os resultados da multiplicação in vitro.

Resultados in vitro de T. catharinensis ainda são incipientes, não se dispondo de protocolos que possibilitem a obtenção de plantas assépticas e com alta taxa de multiplicação. Desse modo, este trabalho teve como objetivo avaliar o efeito da 6-benzilaminopurina (BAP) associada ao ácido naftalenoacético (ANA) no estímulo de brotações aéreas em segmentos cotiledonares e posterior indução do enraizamento em meio de cultivo suplementado com ácido indolbutírico (AIB).

\section{Material e Métodos}

Em câmara de fluxo laminar, segmentos cotiledonares de $1 \mathrm{~cm}$ retirados de plântulas obtidas da germinação in vitro, com 70 dias de idade, foram inoculados em meio de cultura, contendo $100 \%$ dos sais minerais de MS (MURASHIGE; SKOOG, 1962), $30 \mathrm{~g} \mathrm{~L}^{-1}$ de sacarose, $100 \mathrm{mg} \mathrm{L}^{-1}$ de mioinositol, $6 \mathrm{~g} \mathrm{~L}^{-1}$ de polivinilpirrolidona, fungicida Maxim ${ }^{\circledR}$ $2,5 \mu \mathrm{L} \mathrm{L}^{-1} \mathrm{e}$ bactericida Chlortetracycline $0,15 \mathrm{mg} \mathrm{L}^{-1}$. Antes da semi-solidificação com $6 \mathrm{~g} \mathrm{~L}^{-1}$ de ágar e autoclavagem a $1 \mathrm{~atm}, 120^{\circ} \mathrm{C}$ por $20 \mathrm{~min}$, os meios foram acrescidos das combinações de: 0,0 x 0,0; 1,0 x 0,1;2,0 x 0,2; 4,0 x 0,4; 6,0 x $0,6 \mathrm{mg} \mathrm{L}^{-1}$, respectivamente de BAP e ANA.

O delineamento experimental foi inteiramente casualizado, com cinco tratamentos, quatro repetições por tratamento e sete explantes por repetição, totalizando 28 explantes por tratamento. Após 45 dias da inoculação, as avaliações foram realizadas, obtendo-se a percentagem de brotações aéreas, número de brotações e folhas. Por meio de duas amostras de cada repetição foram avaliados comprimento médio do maior broto (mm) e massa fresca (mg).
Para os bioensaios de enraizamento, as brotações aéreas obtidas dos segmentos cotiledonares (experimento anterior) foram cultivadas, em meio de cultura MS completo, acrescidos de ácido indolbutírico (AIB) nas concentrações 0,$0 ; 1,0 ; 2,0$; 4,0 ou $6,0 \mathrm{mg} \mathrm{L}^{-1}$, totalizando cinco tratamentos com três repetições por tratamento e cinco explantes por repetição em delineamento experimental inteiramente casualizado.

Aos 30 dias após a inoculação, as avaliações foram realizadas se obtendo a percentagem de enraizamento, massa fresca (mg), comprimento da maior raiz $(\mathrm{mm})$ e número de raízes.

Para os dois experimentos, o pH do meio de cultura foi ajustado para 5,8 $\pm 0,1 \mathrm{com} \mathrm{NaOH} 0,1 \mathrm{~mol} \mathrm{~L}^{-1}$ ou $\mathrm{HCl} 0,1$ mol L-1. Os tubos foram fechados com papel alumínio e as culturas foram transferidas para sala de crescimento com temperatura de $25 \pm 1{ }^{\circ} \mathrm{C}$ e fotoperíodo de 16 horas (densidade de fluxo de fótons de $35 \mu \mathrm{mol} \mathrm{m} \mathrm{m}^{-2} \mathrm{~s}^{-1}$ fornecida por lâmpadas fluorescentes branca-frias).

Os resultados foram submetidos à análise de variância, sendo as médias das variáveis comparadas pelo teste Scottknott, a 5\% de probabilidade de erro, utilizando o aplicativo Sisvar (FERREIRA, 2011).

\section{Resultados e Discussão}

A organogênese direta de brotações adventícias ocorreu em 89,3 a 96,4\% dos explantes cotiledonares (Figura 1), independente da presença de reguladores de crescimento no meio de cultura, não se observando, portanto, diferenças significativas entre os tratamentos. Segmentos cotiledonares cultivados em meio MS e em diferentes combinações dos fitorreguladores BAP e ANA não formaram plantas completas, apenas brotações aéreas (Figura 2).

Figura 1 - Brotações aéreas obtidas a partir de segmentos cotiledonares de Tabernaemontana catharinensis cultivados in vitro com diferentes concentrações de BAP e ANA. Médias seguidas de mesma letra não diferem entre si pelo teste de ScottKnott a 5\% de probabilidade

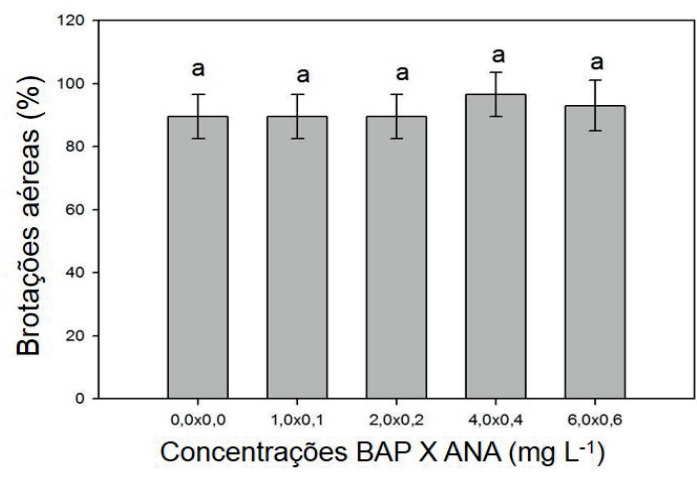

Fonte: Dados da pesquisa 
Figura 2 - Brotações aéreas aos 30 dias após a inoculação de segmentos cotiledonares de Tabernaemontana catharinensis (A); enraizamento in vitro após cultivo em concentração de $6,0 \mathrm{mg} \mathrm{L}^{-1}$ de AIB (B)
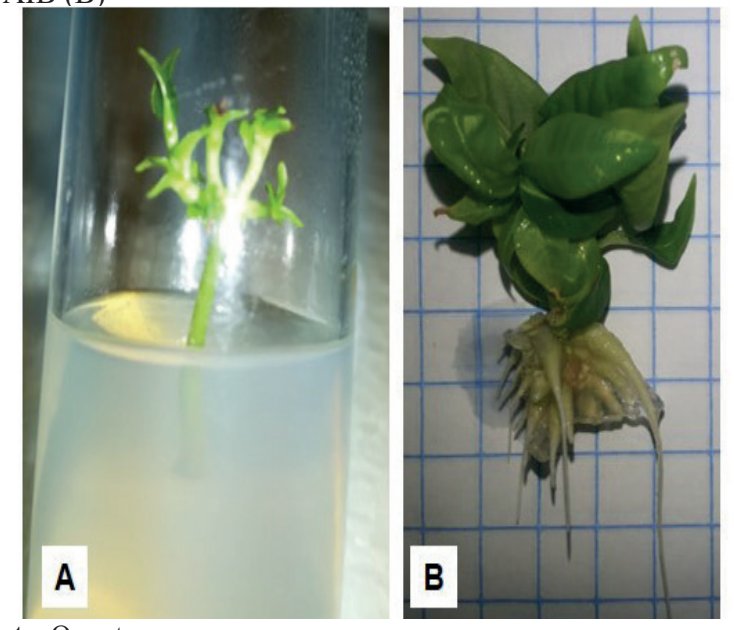

Fonte: Os autores

O processo de morfogênese é controlado pelo balanço hormonal entre auxinas e citocininas. A adição destes fitorreguladores de crescimento em meio de cultura e um balanço adequado entre esses são importantes para desencadear processos organogenéticos em diversas espécies, embora este balanço hormonal seja muito peculiar e influenciado por vários fatores, como espécie, tipo e idade do explante, níveis endógenos de hormônios vegetais e o meio de cultura (SILVA et al., 2012).

Observou-se, no presente trabalho, que não houve a necessidade de fitorreguladores para desencadear a neoformação de parte aérea a partir de segmentos cotiledonares. Estes resultados também foram observados em outras espécies arbóreas como: Aniba rosaeodora, Syzygium cordatum e Tapirira guianensis (JARDIM et al., 2010; DEWIR et al., 2011; GUTIERREZ et al., 2013). A maior capacidade morfogenética de algumas espécies pode estar atrelada com a variabilidade genética, somado aos níveis endógenos de reguladores de crescimento (GEORGE; DEBERGH, 2008).

Além disso, as concentrações associadas de BAP e ANA, na fase inicial da neoformação, não foram satisfatórias para desencadear o processo de formação de raízes, somente brotações aéreas e, consequentemente, não formaram microplantas completas. Do mesmo modo que existem espécies que respondem satisfatoriamente às classes de fitorreguladores (citocininas e auxinas), formando plantas completas diretamente, existem também aquelas que não possuem tal capacidade, em função das características peculiares da espécie (SOUZA; PEREIRA, 2007).

Os valores para número de brotos e folhas, comprimento e a massa fresca de brotações foram maiores nos meios, contendo BAP associado ao ANA (Quadro 1), diferenciando significativamente do tratamento sem fitorreguladores. Para o comprimento das brotações, segmentos cotiledonares expostos às concentrações de 4,0 x 0,4 e $6,0 \times 0,6 \mathrm{mg} \mathrm{L}^{-1}$
(BAP x ANA) apresentaram os maiores valores, em relação às demais concentrações.

Quadro 1 - Valores médios do número de brotos, comprimento de brotações, massa fresca dos brotos e número de folhas de explantes cotiledonares de Tabernaemontana catharinensis A. DC aos 45 dias após a inoculação em meio com diferentes concentrações de BAP e ANA

\begin{tabular}{|c|c|c|c|c|}
\hline $\begin{array}{c}\text { BAP x } \\
\text { ANA (mg } \\
\left.\mathbf{L}^{-1}\right)\end{array}$ & $\begin{array}{c}\mathbf{N}^{\mathbf{0}} \text { de } \\
\text { Brotos }\end{array}$ & $\begin{array}{c}\text { Comp. de } \\
\text { Brotações } \\
(\mathbf{m m})\end{array}$ & $\begin{array}{c}\text { Massa } \\
\text { Fresca dos } \\
\text { Brotos }\left(\mathbf{m g}_{\left.\text {planta }^{-1}\right)}\right.\end{array}$ & $\begin{array}{c}\mathbf{N}^{\mathbf{o}} \\
\text { de Folhas }\end{array}$ \\
\hline $0,0 \times 0,0$ & $1,18 \mathrm{c}$ & $5,01 \mathrm{c}$ & $10,85 \mathrm{~b}$ & $3,83 \mathrm{~b}$ \\
\hline $1,0 \times 0,1$ & $2,08 \mathrm{~b}$ & $11,84 \mathrm{~b}$ & $24,53 \mathrm{a}$ & $7,33 \mathrm{a}$ \\
\hline $2,0 \times 0,2$ & $3,23 \mathrm{a}$ & $11,29 \mathrm{~b}$ & $28,84 \mathrm{a}$ & $7,55 \mathrm{a}$ \\
\hline $4,0 \times 0,4$ & $2,58 \mathrm{a}$ & $14,16 \mathrm{a}$ & $27,74 \mathrm{a}$ & $6,63 \mathrm{a}$ \\
\hline $6,0 \times 0,6$ & $2,70 \mathrm{a}$ & $14,81 \mathrm{a}$ & $28,08 \mathrm{a}$ & $7,03 \mathrm{a}$ \\
\hline $\mathrm{CV}(\%)$ & 22,54 & 16,25 & 10,93 & 22,55 \\
\hline
\end{tabular}

*Médias seguidas de mesma letra na coluna não diferem entre si pelo teste de Scott-Knott a 5\% de probabilidade.

Fonte: Dados da pesquisa.

Como observado nos resultados apresentados, o sinergismo entre os fitorreguladores BAP e ANA na multiplicação das brotações, a partir de segmentos cotiledonares em $T$. catharinensis foram satisfatórios, destacando o efeito benéfico do BAP utilizado em concentrações dez vezes superiores ao ANA. O mesmo atua em maior escala, agindo na divisão celular e na quebra de dormência das gemas axilares, até então inibidas pela dominância apical, estimulando uma maior produção de brotações. É importante destacar também que as concentrações utilizadas neste trabalho não demonstraram efeito fitotóxico para a espécie em estudo (REIS et al., 2008; MONFORT et al., 2012).

Nas concentrações maiores de BAP associadas ao ANA foi possível observar maior individualização dos brotos, consequentemente, ocorrendo maior número de brotações, o que corrobora para um aumento na massa fresca das brotações. Villa et al. (2005) relatam que um maior número de brotos reduz o comprimento dos mesmos. Porém, neste trabalho não foram observadas tais consequências, demonstrando que concentrações adequadas de fitorreguladores são específicas para cada espécie.

$\mathrm{O}$ incremento no número de folhas na etapa de multiplicação é favorável, pois promoverá a origem de um novo broto e, consequentemente, aumentará a produção de novas mudas (COSTA et al., 2010), além de auxiliar na fase de aclimatização. No cultivo in vitro, maior número de folhas poderá proporcionar maior índice de sobrevivência, pela maior captação de energia solar e produção de matéria orgânica através da fotossíntese, auxiliando no processo de aclimatização, na qual a planta passará de uma fase heterotrófica para autotrófica (MOREIRA et al., 2006).

Dados da percentagem de enraizamento, comprimento, massa fresca e número de raízes são apresentados no Quadro 2. Os resultados indicam um efeito significativo da adição de AIB nas variáveis analisadas. Brotações aéreas cultivadas 
em 6,0 $\mathrm{mg} \mathrm{L}^{-1}$ de AIB apresentaram maior percentagem de enraizamento (80\%), comprimento de raiz $(33,1 \mathrm{~mm})$ e massa fresca de raiz (124,9 mg) (Figura 2B). Maior número de raízes foi observada nas concentrações de 4,0 e $6,0 \mathrm{mg} \mathrm{L}^{-1}$ de AIB (5,33 e $6,0 \mathrm{~cm}$, respectivamente), não ocorrendo diferença significativa entre estes tratamentos, porém diferindo dos demais.

Quadro 2 - Percentagem de enraizamento e valores médios de comprimento da maior raiz $\left(\mathrm{COM}_{\text {Raiz }}\right)$, massa fresca $\left(\mathrm{MF}_{\text {Raiz }}\right)$ e número de raízes $\left(\mathrm{N}^{\circ} \mathrm{R}\right)$ de microestacas de Tabernaemontana catharinensis A. DC. avaliadas aos 30 dias após a inoculação em concentrações de AIB

\begin{tabular}{|c|c|c|c|c|}
\hline $\begin{array}{c}\text { AIB } \\
\left(\mathbf{m g ~ L}^{-1}\right)\end{array}$ & $\begin{array}{c}\text { Enraizamento } \\
(\mathbf{\%})\end{array}$ & $\begin{array}{c}\mathbf{C O M}_{\text {Raiz }} \\
(\mathbf{m m})\end{array}$ & $\begin{array}{c}\mathbf{M F}_{\text {Raiz }_{\mathbf{z}}} \mathbf{m g}_{\mathbf{m}} \\
\mathbf{p l a n t a}^{-1} \mathbf{)}\end{array}$ & $\mathbf{N}^{\mathbf{}} \mathbf{R}$ \\
\hline 0,0 & $46,6 \mathrm{~b}$ & $9,2 \mathrm{~d}$ & $36,9 \mathrm{~d}$ & $2,66 \mathrm{~b}$ \\
\hline 1,0 & $46,6 \mathrm{~b}$ & $21,3 \mathrm{c}$ & $53,8 \mathrm{c}$ & $3,66 \mathrm{~b}$ \\
\hline 2,0 & $40,0 \mathrm{~b}$ & $23,2 \mathrm{c}$ & $49,6 \mathrm{c}$ & $3,66 \mathrm{~b}$ \\
\hline 4,0 & $53,3 \mathrm{~b}$ & $27,5 \mathrm{~b}$ & $75,6 \mathrm{~b}$ & $5,33 \mathrm{a}$ \\
\hline 6,0 & $80,0 \mathrm{a}$ & $33,1 \mathrm{a}$ & $124,9 \mathrm{a}$ & $6,00 \mathrm{a}$ \\
\hline CV (\%) & 23,72 & 12,95 & 6,89 & 19,14 \\
\hline
\end{tabular}

*Médias seguidas de mesma letra na coluna não diferem entre si pelo teste de Scott-Knott a 5\% de probabilidade.

Fonte: Dados da pesquisa.

Um importante fator no processo do cultivo in vitro de espécies florestais é a capacidade dos tecidos formarem raízes adventícias e esta depende de vários fatores endógenos e/ou exógenos e suas interações (ROCHA et al., 2008).

O papel das auxinas na indução e no desenvolvimento de raízes tem sido bastante estudado (MONFORT et al., 2012). Brotações aéreas, quando expostas em meios enriquecidos com auxinas sintéticas, maximizam a formação de raízes. Ford et al. (2002) sugerem que o AIB aplicado é rapidamente transportado das raízes até as folhas, ativando uma maior produção de ácido indolacético (AIA), com posterior redistribuição até a região de iniciação radicular, consequentemente, promovendo maior taxa de enraizamento.

Além disso, o efeito positivo para o comprimento, massa fresca e número de raízes nas brotações, com o aumento das concentrações de AIB no meio de cultura, evidencia uma tendência em produzir um sistema radicular mais vigoroso e funcional. Mesmo com concentrações maiores de AIB, não foi observada a formação de calo na base das brotações, sendo benéfico, pois este geralmente dificulta a conexão do sistema vascular entre o caule e a raiz (SANTANA et al., 2008). Quando se obtém um maior número de raízes formadas in vitro, aumenta-se também a área de contato raiz/substrato, refletindo em maior absorção dos nutrientes.

Um sistema radicular limitado acarreta diminuição da biomassa da raiz, reduzindo principalmente a relação raiz/ parte aérea, características indesejáveis no cultivo in vitro, tendo em vista posterior fase de aclimatização, ponto crítico da micropropagação, em função da baixa sobrevivência das plantas, principalmente, ao estresse que sofrem na passagem da condição in vitro para o ex vitro, no que se refere ao transporte de água e nutrientes (MAGGIO et al., 2007).

\section{Conclusão}

A micropropagação de Tabernaemontana catharinensis ocorre em duas fases, a neoformação da parte aérea seguida de cultivo em meio indutor do enraizamento. A formação de brotações aéreas ocorre sem a necessidade de fitorreguladores, porém concentrações 4,0 x 0,4 e 6,0 x 0,6 mg L-1 (BAP x ANA) promovem um incremento em todos os parâmetros analisados. Meio de cultivo enriquecido com $6,0 \mathrm{mg} \mathrm{L}^{-1}$ de AIB potencializa a formação de raízes, possibilitando um maior número de microplantas completas.

\section{Referências}

BÉLO, M. et al. Avaliação do efeito bioinseticida dos extratos de Tabernaemontana catharinensis A. DC. (Apocynaceae) e Zeyheria montana Mart. (Bignoniaceae) sobre a mosca Zaprionus indianus (Díptera: Drosophilidae) (Gupta, 1970). Rev Bras. Biociênc., v.7, n.3, p.235-239, 2009.

COSTA, G.M. et al. Propagação in vitro de Erythrina velutina. Ciênc. Rural, v.40, n.5, p.1090-1096, 2010.

DEWIR Y.H. et al. Micropropagation and detection of important triterpenes in vitro and field grown plants of Syzygium cordatum. J. Med. Plants Res., v.5, n.14, p.3078-3083, 2011.

FERMINO JUNIOR, P.C.P.; PEREIRA, J.E.S. Germinação e propagação in vitro de Cerejeira (Amburana acreana (Ducke) A.C. Smith - Fabaceae). Ciênc. Florestal, v.22, n.1, p.1-9, 2012.

FERREIRA, D. F. Sisvar: a computer statistical analysis system. Ciênc. Agrotecnol., v.35, n.6, p. 1039-1042, 2011.

FORD, Y.Y. et al. Adventitious rooting: examining the role of auxin in easy and a difficult-to-root plant. Plant Growth Regulation, v.36, n.2, p.149-159, 2002. doi: 10.1023/A:1015013025513

FRANCISCO, J.P. et al. Qualidade de mudas de manjericão (Ocimum basilicum L.) em casa de vegetação submetida a diferentes substratos e concentração de ácido indolbutírico. Rev Agronegócio Meio Amb., v.8, n.2, p.401-419, 2015.

GEORGE E.F; DEBERGH P.C. Micropropagation: uses and methods. In: GEORGE, E.F, HALL, M.A; KLERK, G.J. Plant propagation by tissue culture. The Background. Dordrecht: Springer. 2008, p.29-64.

GUTIERREZ, I.E.M. de et al. Multiplicação in vitro de Tapirira guianensis Aubl. (Anacardiaceae). Rev Ceres, v.60, n.2, p.143151, 2013.

JARDIML.S. et al. Efeito de diferentes reguladores de crescimento na regeneração in vitro de pau-rosa (Aniba rosaeodora Ducke). Acta Amazonica, v.40, n.2, p.275-280, 2010. doi: 10.1590/S004459672010000200005.

LORENZI, H. Árvores brasileiras: manual de identificação e cultivo de plantas arbóreas nativas do Brasil. Nova Odessa: Instituto Plantarum, 2009. p.384.

MAGGIO, A. et al. Salt stress response in tomato beyond the salinity tolerance threshold. Environmental and Experimental Botany, v.59, n.3, p.276-282, 2007. doi: 10.1016/j. envexpbot.2006.02.002

MAIA, J.T.L.S. et al. Influência do cultivo em consórcio na produção de fitomassa e óleo essencial de manjericão (Ocimum basilicum L.) e hortelã (Mentha x villosa Huds.). Rev. Bras. Plantas Med., v. 11, n.2, p.137-140, 2009.

MONFORT, L.E.F. et al. Efeito do BAP no cultivo in vitro de Ocimum selloi Benth. Rev. Bras. Plantas Med., v.14, n.3, p.458- 
$463,2012$.

MORAIS, T.P.; ASMAR, S.A.; LUZ, J.M.Q. Reguladores de crescimento vegetal no cultivo in vitro de Mentha x Piperita L. Rev. Bras. Plantas Med., v.16, n.2, p.350-355, 2014.

MOREIRA, M.A. et al. Efeito de substratos na aclimatização de mudas micropropagadas de abacaxizeiro cv. Pérola. Ciênc. Agrotecnol., v.30, n.5, p.875-879, 2006. doi: 10.1590/S141370542006000500008

MURASHIGE, T.; SKOOG, F. A revised medium for rapid growth and bio assays with tobacco tissue cultures. Physiol. Plantarum, v.15, n.3, p.473-497, 1962. doi: 10.1111/j.13993054.1962.tb08052.x

NEPOMUCENO, C.F. et al. Respostas morfofisiológicas in vitro de plântulas de Anadenanthera colubrina (Vell.) Brenan var. cebil (Griseb) Altschul. Rev. Arvore, v.33, n.3, p.481-490, 2009.

PEREIRA, C. et al. Antioxidant and antimycobacterial activities of Tabernaemontana catharinensis extracts obtained by supercritical $\mathrm{CO}_{2}+$ cosolvent. J. Med. Food, v.8, n.4, p.533-538, 2005. doi: 10.1089 /jmf.2005.8.533

PEREIRA, P.S. et al. Chemical constituents from Tabernaemontana catharinensis root bark: a brief NMR review of indole alkaloids and in vitro cytotoxicity. Quim. Nova, v.31, n.1, p.20-24, 2008. doi: 10.1590/S0100-40422008000100004

PIANA, M. et al. Phytochemical analysis and antioxidante capacity of Tabernaemontana catharinensis A. DC. Fruits and branches. Anais Acad. Bras. Ciênc., v.86, n.2, p.881-888, 2014.
PINHAL, H.F. et al. Aplicações da cultura de tecidos vegetais em fruteiras do Cerrado. Ciênc. Rural, v.41, n.7, p.1136-1142, 2011.

REIS, E.S. et al. Influência do meio de cultura na germinação de sementes in vitro e taxa de multiplicação de Melissa officinalis L. Rev. Ceres, v.55, n.3, p.160-7, 2008.

ROCHA, S.C. et al. Micropropagação de Cabralea canjerana. Rev. Árvore, v.31, n.1, p.43-50, 2007. doi: 10.1590/S010067622007000100006

SANTANA, J.R.F. et al. Estímulo do comportamento fotoautotrófico durante o enraizamento in vitro de Annona glabra L., II. Aspectos da anatomia da folha antes da aclimatização. Ciênc. Agrotecnol., v. 32, n. 2, p.640-644, 2008.

SILVA, A.L.L. et al. Germinação in vitro de sementes e indução de calos em plântulas, cotilédones e anteras de porongo (Lagenaria siceraria (Mol.) Stand.) - Cucurbitaceae. J. Biotechnol. Biodiversity, v.3, n.4, p.117-126, 2012.

SOUZA, A.V.; PEREIRA, A.M.S. Enraizamento de plantas cultivadas in vitro. Rev. Bras. Plantas Med., v.9, n.4, p.103-117, 2007.

VILLA, F. et al. Multiplicação in vitro da amoreira-preta 'Ébano' em diferentes concentrações de meio MS e BAP. Ciênc. Agrotecnol., v.29, n.3, p.582-589, 2005.

XAVIER, A.; WENDLING, I.; DA SILVA, R.L. Silvicultura clonal: princípios e técnicas. Viçosa: Universidade Federal de Viçosa, 2009. 